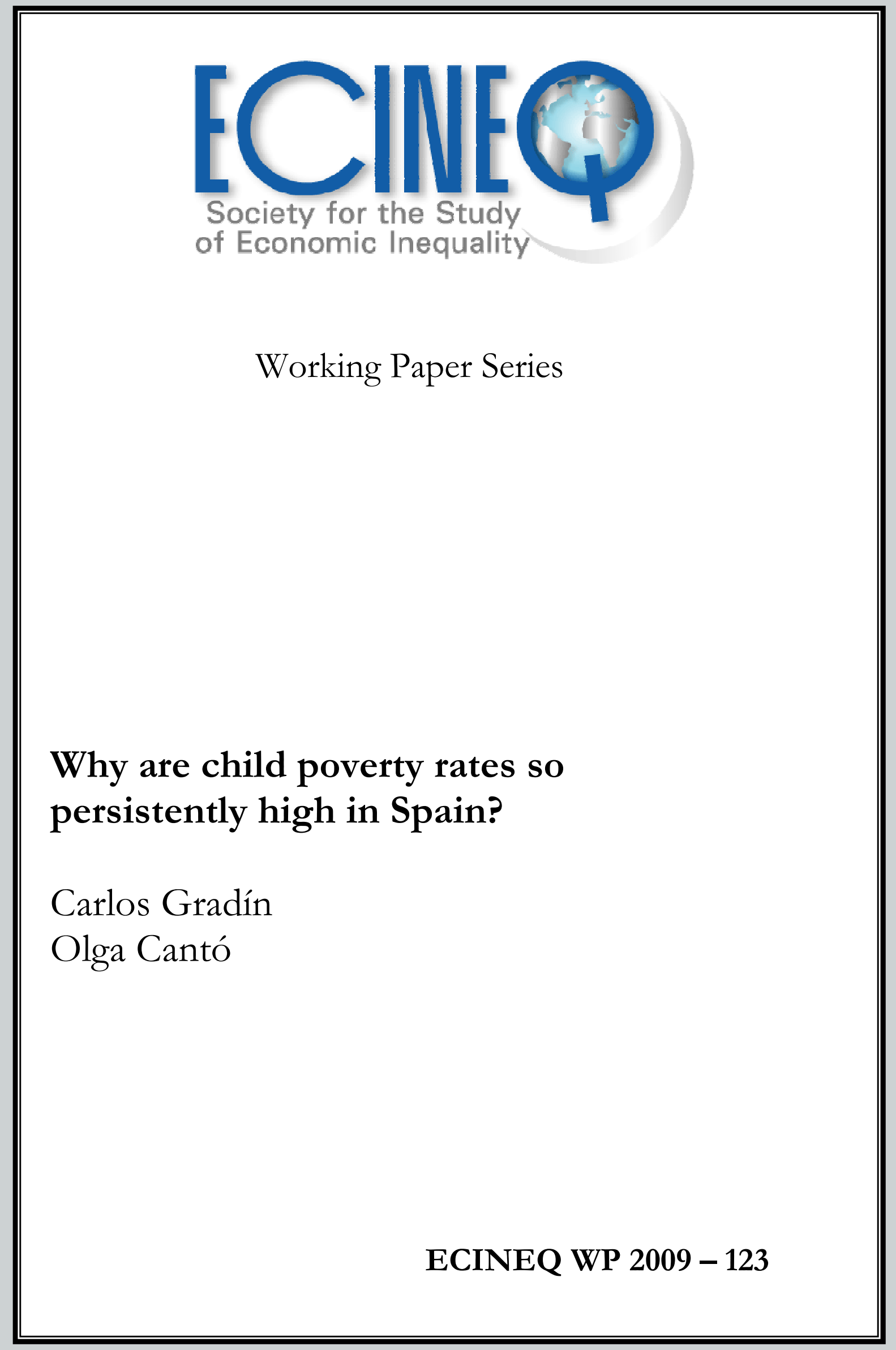




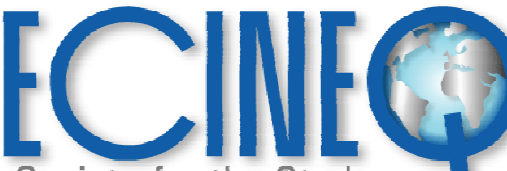

Society for the Study

of Economic Inequality
ECINEQ 2009-123

August 2009

WWW.ecineq.org

\title{
Why are child poverty rates so persistently high in Spain?*
}

\author{
Carlos Gradín \\ Universidade de Vigo \\ Olga Cantó \\ Instituto de Estudios Fiscales and Universidade de Vigo
}

\begin{abstract}
Poverty rates among households with children in Spain have been shown to be persistently higher than those among households without children. These higher rates prevail for chronic, transitory and, most remarkably, for recurrent poverty. In order to study the dynamics of poverty transitions in Spain we estimate a dynamic random effects probit model that controls for unobserved heterogeneity and initial conditions using the European Community Household Panel. Our results show differential effects of several individual and household characteristics on the probability of being poor for households with and without children. Of special interest is how labour instability factors can help to explain the outstandingly higher recurrence in poverty among households with children in Spain, compared with other countries.
\end{abstract}

Keywords: children, poverty dynamics, random-effects, Spain.

JEL classification: D1, D31, I32.

* We would like to thank participants in the Low Pay, Low Skill, and Low Income (LOPSI) Workshop held in Milan for their comments. We also acknowledge financial support from the Spanish Ministerio de Educación y Ciencia (grant SEJ2007-67911-C03-01/ECON).

Corresponding author: Olga Cantó, Instituto de Estudios Fiscales, Avda. Cardenal Herrera Oria, 378, 28035 Madrid, Tel: +34 91 3398930, Fax: +34 913398733, e-mail: ocanto@uvigo.es 


\section{Introduction}

The literature on poverty dynamics has highlighted that poverty is a largely dynamic phenomenon. Results from the OECD (2001) on various developed countries show that approximately a 5 percent of the non-poor population enters poverty each year and a 45 percent of those below the poverty threshold at one moment in time are able to leave that situation at a subsequent moment. In fact, as Jenkins and Schluter (2003) underlined, the study of transitions is crucial to understand poverty statics because the stock of poor people in a given year depends on the previous year's stock and the net result of the flows into and out of poverty. If poverty rates are constant along a given period, differences in poverty rates by subgroups depend on differences in poverty entry and exit rates. Further, the analysis of entry and exit rates has strong implications in results on dynamics given that the flows into and out of poverty will be important determinants of the level of persistent versus transitory poverty.

The emergence of new forms of poverty in industrialized countries during the last decades of the twentieth century has fostered the analysis of child poverty in various countries. The rise of unemployment, particularly long-term, as well as the rise in temporary employment seems to be strongly linked to the causes of poverty risk in recent years. Children are a particularly vulnerable group among the poor. According to evidence offered in various chapters in Huston (1991) or Machin (1998), the consequences of the experience of poverty in childhood are likely to persist for long since the earnings of parents play an important role in the determination of the cognitive achievement of children and the chances for economic mobility across generations. McLoyd and Wilson (1991) point out that it is reasonable to suppose that the stresses of living in poverty will take the toll on parents as well as on children.

The level and evolution of child poverty has become an important concern for social policy in many rich countries in recent times, particularly since UNICEF (2005) published a report where many developed OECD countries registered an increasingly high rate of child deprivation. Spain is one of the European Union countries where the level of child poverty has been highest during the last decade. Child poverty rates in Spain have been consistently over 23 percent since 1994 while adult poverty rates, even if at high levels too, did not go beyond a 19 percent. Our calculations, using data from the European Community Household Panel (ECHP from here onwards) show that, comparing households at childbearing ages, the gap between the poverty rates for individuals living in households with children and those 
living in households without children in Spain increased during the nineties. Moreover, the incidence of chronic poverty on individuals in households with children is more than double that of those living in households without children. However, poverty risk in Spain has also been shown to have an important transitory component (OECD 2001, 2008). In fact, results in Cantó et al. (2008) point out that Spain is a country with a high percentage of transitory poverty in the European context, however approximately one third of total transitory poverty is recurrent. The distinction between "recurrent" and "non-recurrent" transitory poverty is relevant because it modifies the potentially positive effect of registering a fluid poverty phenomenon. As Gardiner and Hills (1999) noted, transitory poverty must be adequately interpreted taking into account to what extent there is poverty recall. The incidence of recurrent poverty in Spain is high for individuals living in households where the household head is potentially active in the labour market (Cantó et al., 2008). In fact, our results will show that the incidence of recurrent poverty is particularly high for individuals in households with children.

In this paper we analyse the dynamics of poverty among households with and without children in Spain. More specifically, we first document the distinctive features of child poverty in Spain compared with other EU countries. Then, using a random-effects dynamic probit model we study the role played by true state dependence and households characteristics in order to explain the higher rates of both chronic and recurrent poverty among households with children in comparison with the rest. True state dependence is the remaining persistence in poverty from one period to the next once all observed and unobserved differences in characteristics across households have been controlled for.

State dependence resumes the expected 'scarring' effect promoting persistence that may be linked to, for example, an increasing depreciation of human capital, a reduction of one's social network, or simply the adverse effect of the loss of hope in returning to a better economic situation. In order to estimate its value our econometric model needs to properly deal with unobserved heterogeneity (also called individual-specific effects) and endogenous initial conditions. This value is crucial for social policy design. As far as poverty is driven by state dependence helping individuals to jump over the poverty line is expected to have a longterm effect reducing their probability of being poor also in future periods. If, on the contrary, poverty is mainly driven by households' adverse characteristics, social policies should focus 
on removing those more directly related to a higher poverty risk. The comparison of the magnitude of true state dependence for both groups will help to disentangle the various channels through which households with children face a higher risk of being poor than childless households. Thus, if, for instance, we find a larger true state dependence for individuals in households with children this would partially explain why child poverty is more chronic than adult poverty. If, on the contrary, state dependence is smaller for individuals in households with children this would explain why we find a higher poverty recurrence for individuals in this group. Further, if state dependence is similar for both groups we aim to find out if differences in poverty rates are the consequence of significant distinct effects of certain explanatory variables on the probability of leaving poverty for each household type. We believe that it is particularly interesting to check the extent to which the instability factors that characterize the Spanish labour market, such as the high unemployment rate and the outstandingly high rate of temporary jobs are distinctively affecting the poverty risk of households depending on the presence of children.

The paper is organised as follows. The first section introduces the features of child poverty in Spain while the second section discusses the determinants of transitions out of poverty and presents the econometric model. The third section puts forward our empirical results and the final section summarizes the main findings.

\section{The statics and dynamics of child poverty in Spain and other EU countries.}

Child poverty estimates in various rich countries using household micro-data suggest that children are generally over-represented among the poor. At the European level (EU-15), Portugal, Italy, Ireland, Spain and the UK, in this order, are the countries that register a higher proportion of children living in poor households in 2004 (Eurostat, 2007 or UNICEF, 2005). Interestingly, in the rest of the countries of the EU-15 child poverty rates are always over adult poverty rates, except in Nordic countries like Denmark, Finland or Sweden.

Any research regarding child poverty in the case of Spain needs to acknowledge the strong changes in the demographic and socioeconomic structure of the society in the last 40 years. Regarding the structure of the population, from the 1960s to the 1990s, Figure 1 shows the gradually increasing decline in the relative weight of children under 18 in the population that

amounted to almost a 26 percent reduction between 1960 and 2001. It is noticeable that the 
decline was particularly large in the youngest age group (children under 5) reaching a 35 percent, clearly in line with the large decline in the fertility rate in Spain since 1975 until 1995 as plotted in Figure 2. This rate reached in the mid-nineties one of the lowest fertility rates in Europe and, most probably, in the whole world, 1.18 children per fertile woman (Ahn and Mira, 2001, or Adserá, 2004).

Figure 1. Evolution of Children in the Population, Spain, 1960-2001. INE, Census data.

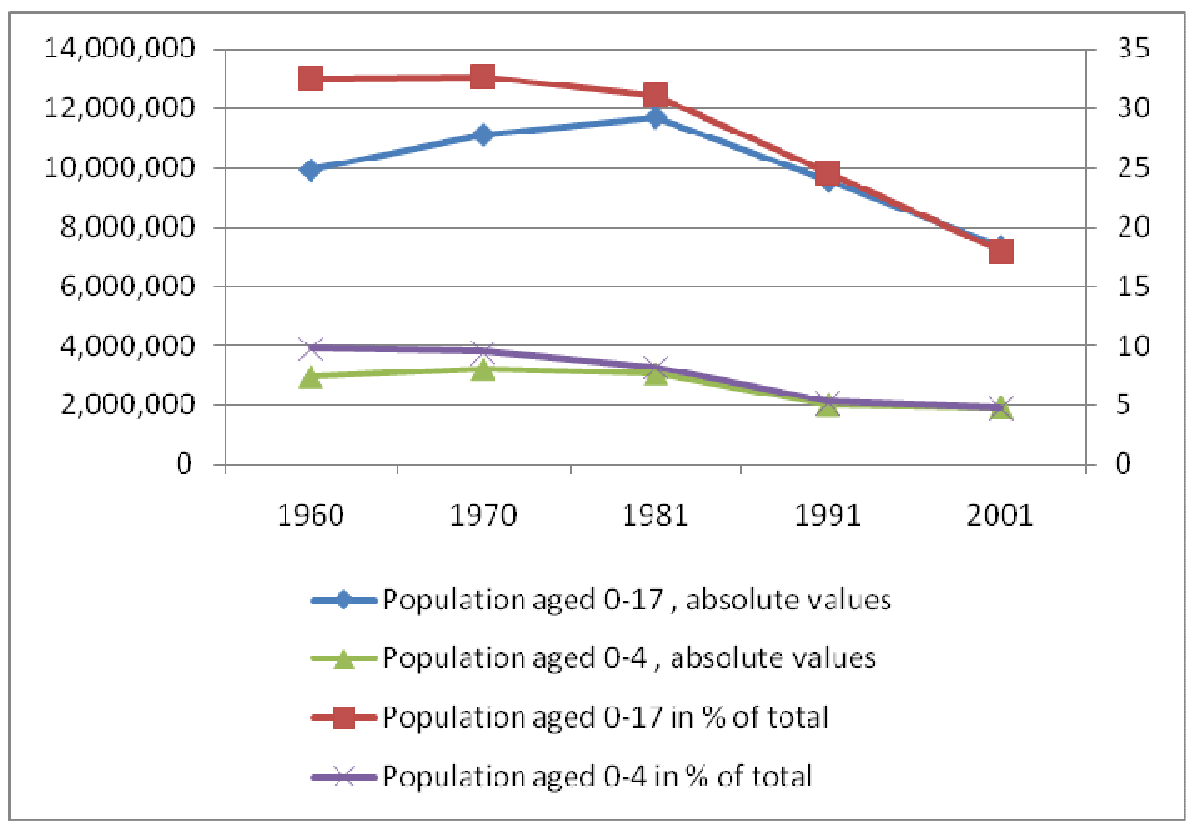


Figure 2. Evolution of age-specific Fertility rates, Spain, 1975-2006.

INE, Census data. Number of children born to 1000 females of the selected age group.

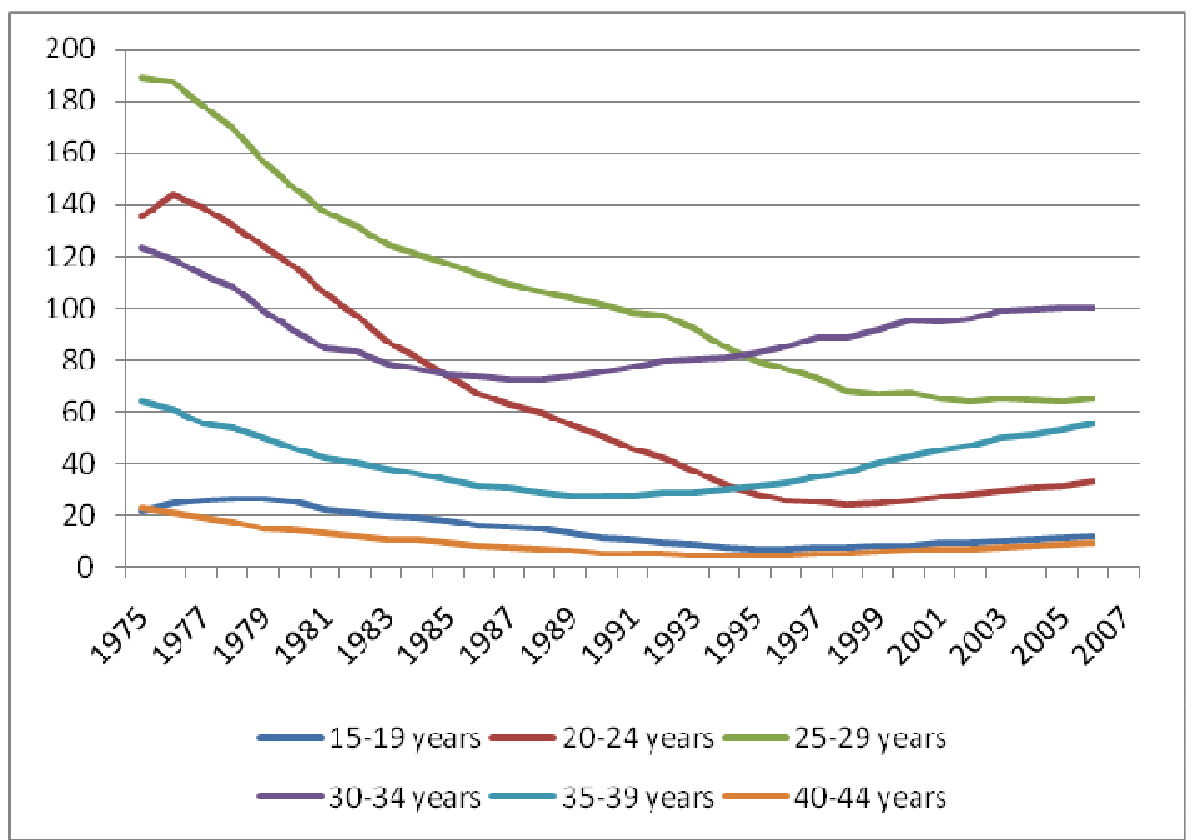

Poverty trends for the entire population suggest that during the seventies and eighties and until the very beginning of the nineties there was a significant reduction in monetary poverty in Spain. This decline was clearer using income and was only very slight using expenditure. Child poverty rates have always been over non-elderly-adult poverty rates and changes over that period seem hardly significant despite the major socioeconomic transformation that took place in the country. ${ }^{1}$ Ayala et al. (2006) show that, since 1994, in a context of stability of overall poverty rates, the relative economic position of households with children has deteriorated through the increasing incidence of poverty on low-wage household heads and the strong increase in the poverty risk of lone-parent households who, in recent years, have consistently increased their demographic weight. These authors also find an increase in the dependence of child welfare on the labour market incomes of adults within their household while the number of children in households whose head is not occupied has diminished

\footnotetext{
${ }^{1}$ See Cantó and Mercader (2002), Ayala et al. (2006, 2008) or Ayala and Cantó (2009). We must note that for the eighties and nineties the use of expenditure makes the gap between relative poverty rates of children and adults smaller than when using income (Cantó and Mercader, 2002). Nevertheless, as in the case of the rest of the population, in terms of absolute poverty rates and non-monetary indicators of well-being, during the seventies, eighties and nineties, there was a substantial improvement in child welfare in Spain related to the generalized improvement in household income, health and education indicators such as infant and under-5 mortality rates and primary and secondary school net enrolment ratios (Cantó and Mercader, 2002).
} 
between 1994 and 2001. Figure 3 shows that comparing households at childbearing ages during the same period, the gap between the poverty rates for individuals living in households with children and those living in households without children clearly increased. ${ }^{2}$

\section{Figure 3. Poverty rate gap in percentage points between individuals in households with and without children: 1994-2000.}

ECHP 1994-2000. Poverty line 60\% median equivalent household income and contemporaneous information on incomes and characteristics.

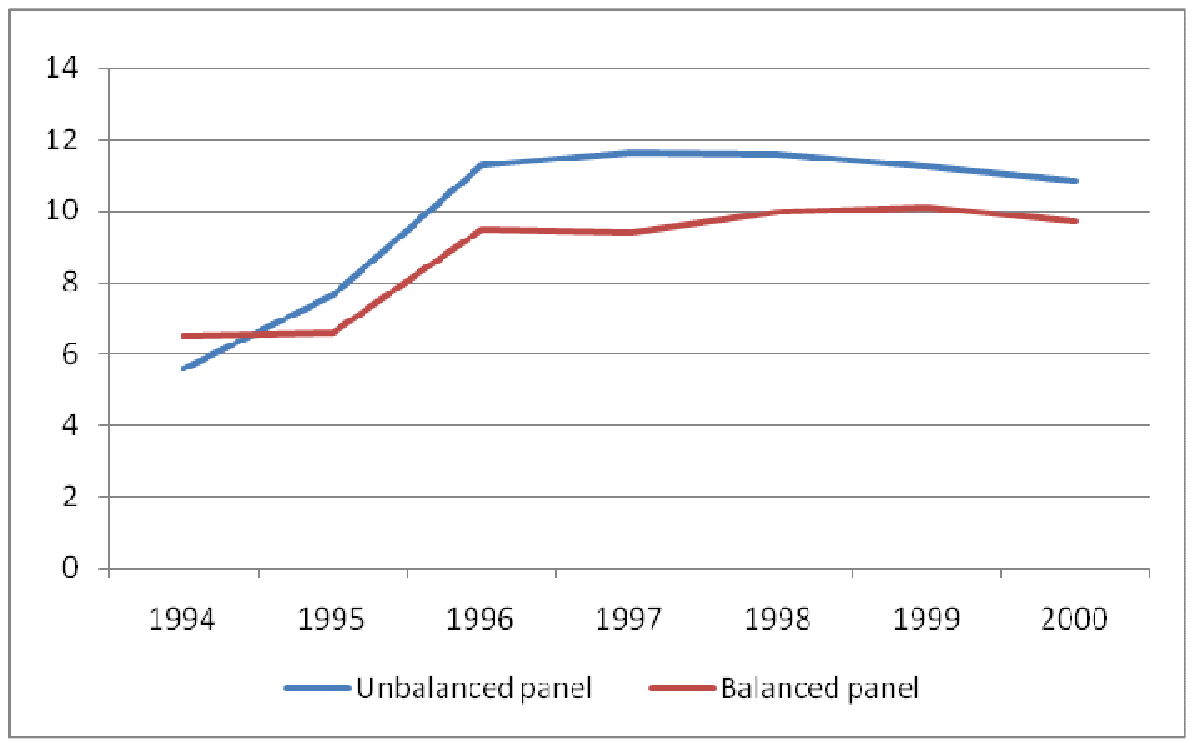

Taking the information on poverty rates at one point in time can, however, obscure the necessary distinction between children whose poverty is relatively transitory with that experienced by those who live in persistent or chronic poverty. In fact, in a recent publication, Cantó et al. (2008) have underlined the relative importance of transitory poverty in Spain, particularly for the group of households whose head is potentially active in the labour market. Huston (1991) recalls that even if transitory poverty, in general, entails fewer social and environmental risks than chronic poverty, it nonetheless can have a lasting impact on children's development given that large fluctuations in family income may force the family to change neighbourhoods and schools and to eliminate "extras" such as recreational activities, lessons and new clothes. All these goods may most directly affect children's welfare. Moreover, if transitory poverty is mostly recurrent we should recall that income volatility is

\footnotetext{
${ }^{2}$ In all our analysis in this paper we use data from the ECHP. An individual is classified as poor if living in a household whose equivalent household income using a modified OECD scale is below 60 percent median equivalent household income the corresponding year. Incomes have been adjusted to be contemporaneous to characteristics, see results about samples in Tables A.1 and A.2 in the Appendix. For more details of the methodology used for this adjustment see Arranz and Cantó (2009).
} 
likely to create emotional stress for parents, which, in turn, may lead some of them to be more punitive to the children - see Emery et al. (1984) or McLoyd (1998). This last point underlines the importance in separating recurrent transitory poverty from non-recurrent transitory poverty. In fact, results in Cantó et al. (2008) offer a measure of the importance of persistent versus transitory poverty in Spain distinguishing between two levels of chronic poverty and, most importantly in our case, separating recurrent from non-recurrent poverty. The results obtained in this paper indicate that up to one third of transitory poverty in Spain is of a recurrent nature while this percentage is significantly smaller in other European countries such as Portugal, France, UK, Germany or Denmark.

Making the same distinction by population subgroups in Figure 4 we have that the incidence of chronic poverty on individuals cohabiting in households with children in Spain is more than double that of those living in households without children, figure that is only below that of the UK. In contrast, countries like Denmark register precisely the reverse. Regarding transitory poverty, Portugal, the UK and Spain show the highest differential in transitory poverty incidence between individuals in households with children and the rest. In the particular case of Spain the difference is larger for individuals observed from two to four years in poverty (out of seven) than for those in poverty for just one year.

\section{Figure 4. Incidence ratios of dynamic poverty for individuals in households with children with respect to those in households without children (1994-2000) ECHP 1994-2000. Poverty line 60\% median equivalent household income and contemporaneous information on incomes and characteristics}

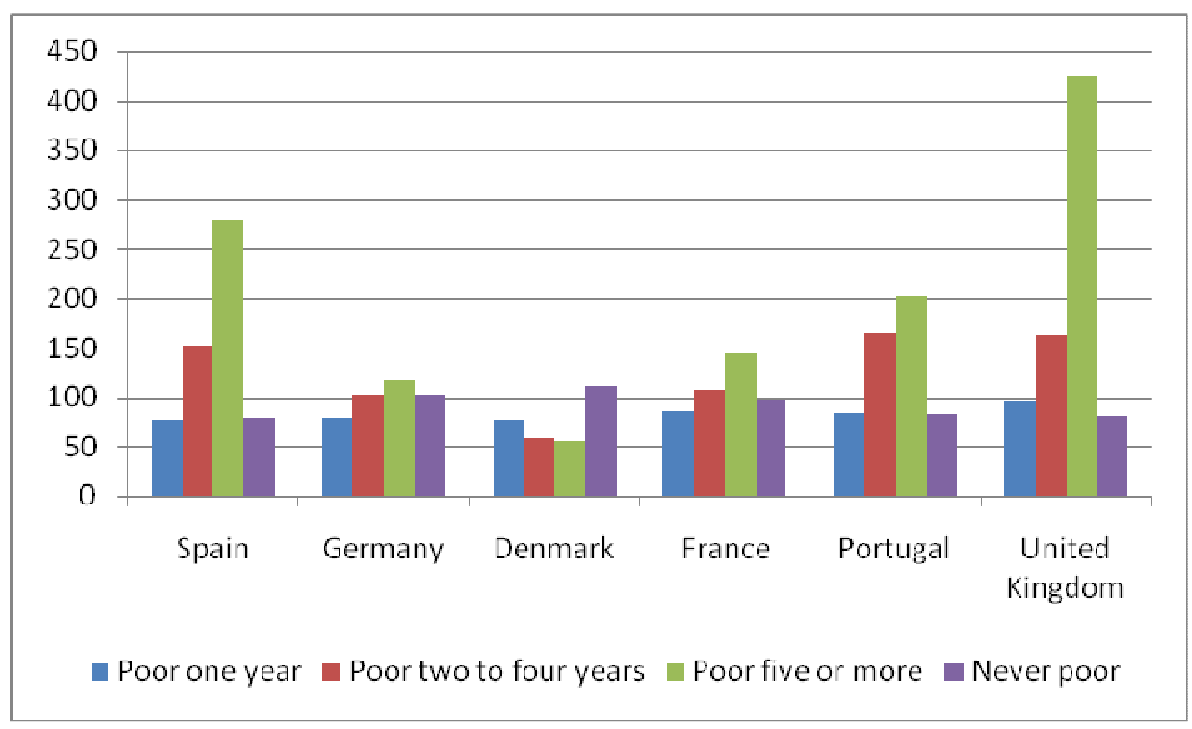


Indeed, if we undertake a deeper analysis of the dynamics of poverty we find significantly higher poverty duration for individuals in households with children than for those in households without children. Results in Table 1 show that in the case of Spain, in a similar way as in the other selected European countries, individuals in households with children suffer a higher level of persistent poverty than households without children. In fact, in Spain 3 percent of individuals in households with children were poor during the whole period of observation, this result almost triples the percentage of individuals in the same situation but living in childless households (a 1.1 percent). At the same time, near to a half of the population in households with children in Spain, a 45.6 percent, were found to be transitorily poor, compared to a 34.4 percent among households without children. ${ }^{3}$ This gap is the largest among the selected countries and contrasts with that found for Denmark or France where transitory poverty is either lower for the former group or similar for both. Transitory poverty can be of two different types: recurrent, when there are repeated poverty spells, and pure or non recurrent, when there is only one single spell. The distinctive fact of higher transitory poverty in households with children in Spain is driven by the significantly higher rate of recurrent poverty in this group (23.6 percent of the total population and nearly a half of those ever poor) which more than doubles that of individuals in households without children in the same country (10.6 and almost 30 percent respectively). These figures on recurrent poverty are well over those that can be obtained for individuals in other countries. ${ }^{4}$

\footnotetext{
${ }^{3}$ We here define as transitory poor all individuals living in households that are found to be below the poverty line between one and six years out of seven.

${ }^{4}$ In fact, out of the group of European countries considered the only one whose results are close to those obtained for Spain is Portugal with a 16.6 percent of the population in transitory and recurrent poverty (a 38 percent of the ever poor). See Cantó et al. (2008) for a detailed analysis of poverty dynamics in Spain.
} 
Table 1. Chronic, Transitory and Recurrent Poverty in various EU countries. Individuals in households whose head is between 18 and 65 years of age: Households with and without children

ECHP 1994-2001. Poverty line is $60 \%$ of the median contemporaneous adjusted household income

\begin{tabular}{|l|c|c|c|c|c|c|c|c|c|c|c|c|}
\hline & \multicolumn{2}{|c|}{ Spain } & \multicolumn{2}{|c|}{ Germany } & \multicolumn{2}{|c|}{ Denmark } & \multicolumn{2}{|c|}{ France } & \multicolumn{2}{|c|}{ Portugal } & \multicolumn{3}{|c|}{ UK } \\
\hline & $\begin{array}{c}\text { Ever } \\
\text { poor }\end{array}$ & Total & $\begin{array}{c}\text { Ever } \\
\text { poor }\end{array}$ & Total & $\begin{array}{c}\text { Ever } \\
\text { poor }\end{array}$ & Total & $\begin{array}{c}\text { Ever } \\
\text { poor }\end{array}$ & Total & $\begin{array}{c}\text { Ever } \\
\text { poor }\end{array}$ & Total & $\begin{array}{c}\text { Ever } \\
\text { poor }\end{array}$ & Total \\
\hline Sample & 3,181 & 7,113 & 2,174 & 8,205 & 545 & 2,497 & 2,284 & 7,277 & 2,618 & 6,386 & 1,891 & 5,624 \\
\hline $\begin{array}{l}\text { Households } \\
\text { with children }\end{array}$ & & & & & & & & & & & & \\
\hline Total ever poor & 100 & 48.6 & 100 & 25.8 & 100 & 18.8 & 100 & 31.8 & 100 & 43.8 & 100 & 38.3 \\
\hline $\begin{array}{l}\text { Chronic poverty } \\
\text { (seven years poor) }\end{array}$ & 6.1 & 3.0 & 7.1 & 1.8 & 2.0 & 0.4 & 8.1 & 2.6 & 10.2 & 4.5 & 7.8 & 3.0 \\
\hline $\begin{array}{l}\text { Transitory poverty } \\
\text { (one to six years poor) }\end{array}$ & 93.9 & 45.6 & 92.9 & 24 & 98 & 18.4 & 91.9 & 29.2 & 89.8 & 39.3 & 92.2 & 35.3 \\
\hline $\begin{array}{c}\text { Recurrent } \\
\text { (two or more spells) }\end{array}$ & 48.6 & 23.6 & 31.4 & 8.1 & 13.4 & 2.5 & 33.5 & 10.6 & 37.9 & 16.6 & 32.3 & 12.4 \\
\hline $\begin{array}{c}\text { Non recurrent } \\
\text { (one single spell) }\end{array}$ & 45.4 & 22.0 & 61.5 & 15.8 & 84.6 & 15.9 & 58.4 & 18.6 & 52 & 22.7 & 59.9 & 23.0 \\
\hline $\begin{array}{l}\text { Households } \\
\text { without children }\end{array}$ & & & & & & & & & & & & \\
\hline Total ever poor & 100 & 35.5 & 100 & 27.6 & 100 & 27.2 & 100 & 30.4 & 100 & 31.6 & 100 & 24.0 \\
\hline $\begin{array}{l}\text { Chronic poverty } \\
\text { (seven years poor) }\end{array}$ & 3.1 & 1.1 & 4.6 & 1.3 & 0 & 0 & 3.2 & 1.0 & 8.6 & 2.7 & 3.0 & 0.7 \\
\hline $\begin{array}{c}\text { Transitory poverty } \\
\text { (one to six years poor) }\end{array}$ & 96.9 & 34.4 & 95.4 & 26.3 & 100 & 27.2 & 96.8 & 29.4 & 91.4 & 28.9 & 97 & 23.3 \\
\hline $\begin{array}{c}\text { Recurrent } \\
\text { (two or more spells) }\end{array}$ & 29.8 & 10.6 & 23.2 & 6.4 & 25.5 & 6.9 & 29.4 & 9.0 & 20.5 & 6.5 & 24.8 & 5.9 \\
\hline $\begin{array}{c}\text { Non recurrent } \\
\text { (one single spell) }\end{array}$ & 67.2 & 23.8 & 72.2 & 19.9 & 74.5 & 20.3 & 67.3 & 20.5 & 70.9 & 22.4 & 72.2 & 17.3 \\
\hline
\end{tabular}

Note: These results are obtained for those present in the panel during eight interviews (pure panel) and using longitudinal attrition weights.

\section{The determinants of transitions out of poverty: A dynamic random effects probit model}

The analysis of the poverty transitions was initiated in the United States during the eighties, mainly as a result of the availability of a mature and reliable longitudinal data survey: the Panel Survey of Income Dynamics (PSID), ongoing since 1968. In the European context it is only in the beginning of the nineties that Duncan et al. (1993) try to compare, for the first time, the duration of poverty in a group of countries using a variety of data sources. Fortunately for the development of this literature, in 1994 the European Statistical Office decided to obtain accurate and comparable longitudinal data information for most countries in the European Union initiating the ECHP Survey which, after some years, has become a basic tool for the analysis of social cohesion dynamics in the European Union. The exploitation of this dataset, together with 
some nationally based panels available for some particular countries, has allowed a large list of researchers to present plausible answers to important issues related to the duration and persistence of poverty in Europe. Unfortunately the new EU-SILC database that replaced ECHP as the main source of information for EU monitoring on poverty since 2004, has a more limited potential use for the analysis of poverty dynamics because it is of a shorter duration (4 years) and a different panel structure (rotating panel).

In estimating the probability of being poor, we use a dynamic random effects probit model following the Stewart (2007)'s analysis of unemployment dynamics. This model, applied to our framework, allows us to incorporate important aspects that the literature on poverty analysis in recent years has stressed to be crucial for the adequate measure of persistence in poverty, such as the treatment of unobserved heterogeneity and the initial conditions problem. ${ }^{5}$ Our approach can be classified within the so-called first-order Markovian transition models, in which individual's present poverty status depends on the previous one. Among them, it is a lagged dependent variable model given that all the previous year information on household characteristics enters the model through the lagged dependent variable in the right hand side of the equation. ${ }^{6}$

In our context, the individual latent poverty propensity $y_{i t}^{*}$ at any year is specified as:

$$
y_{i t}^{*}=\not y_{i t-1}+x_{i t}^{\prime} \beta+\varepsilon_{i}+u_{i t}
$$

where the subscript $i$ indexes individuals and $t$ indexes time periods, with $(i=1, \ldots, N ; t=2, \ldots, T) . N$ is taken to be large and $T$ is small and regarded as fixed, so that asymptotics are on $N$ alone. Given that not all individuals are observed the same number of

\footnotetext{
${ }^{5}$ Unobserved heterogeneity captures the fact that individuals may be heterogeneous with respect to some unobserved characteristics that directly influence their probability of leaving poverty (i.e. being lazy, being an alcoholic or drug consumer, having special abilities, etc.). Accounting for initial conditions is also important because individuals in poverty at first interview are not a random-sample of the population.

${ }^{6}$ An alternative approach to study transition probabilities dealing with unobserved heterogeneity and initial conditions under different assumptions about the nature of the Markovian dynamic process is the endogenous switching model used in Cappellari and Jenkins (2004).
} 
interviews, the panel we use is unbalanced. ${ }^{7}$ The observed binary poverty status of the $i$ th individual is defined as:

$$
y_{i t}=\left\{\begin{array}{c}
1 \text { if } y_{i t}^{*}>0 \\
0 \quad \text { else }
\end{array}\right.
$$

Latent poverty propensity depends on what was the poverty outcome in the previous period, $y_{i t-1}$, this capturing that anyone experiencing a poverty spell today is much more likely to experience it again in the future (state dependence). In order to be sure that this is true state dependence and is not just only reflecting that some individuals are more persistent in poverty because of their adverse characteristics, we need to control for both observed and unobserved heterogeneity across individuals. For that reason, $x_{i t}$ is a vector of explanatory variables that include several contemporary households' characteristics which are available in the survey and that might affect their ability to obtain income (observed heterogeneity), such as household type, education level or labour market performance of household members. Further, $\varepsilon_{i}$ takes into account any other persistent attributes of household members (such as abilities, preferences, etc) which may also influence the likelihood of being poor at any given period (unobserved heterogeneity). In order to avoid the violation of the orthogonality condition in random effects models, correlation of these individual-specific terms with the observed characteristics is treated by assuming a relationship of the form $\varepsilon_{i}=\overline{x_{i}} a+\alpha_{i}$ (Mundlak, 1978 and Chamberlain, 1984), where $\overline{x_{i}}$ is a vector with the time means of explanatory variables, with the exception of intrinsically time-varying variables such as age, and $\alpha_{i} \sim$ iid $N\left(0, \sigma_{\alpha}^{2}\right)$ are the individual-specific effects which are independent of $x_{i t}$ and $u_{i t}$ for all $i, t$. Equation (1) can be then rewritten as:

$$
y_{i t}^{*}=\gamma y_{i t-1}+x_{i t}^{\prime} \beta+\bar{x}_{i}^{\prime} a+\alpha_{i}+u_{i t}
$$

Additionally, we assume the serially independent error term $u_{i t} \sim N\left(0, \sigma_{u}^{2}\right)$ and the composite error term $v_{i t}=\alpha_{i}+u_{i t}$ equally correlated in whatever two different periods:

\footnotetext{
7 The use of an unbalanced panel requires the assumption that the unobservable determinants of attrition are not correlated with the unobservables determining poverty (Cappellari and Jenkins, 2008).
} 


$$
\lambda=\operatorname{Corr}\left(v_{i t}, v_{i s}\right)=\frac{\sigma_{\alpha}^{2}}{\sigma_{\alpha}^{2}+\sigma_{u}^{2}}
$$

Normalizing $\sigma_{u}^{2}=1$, the transition probability for individual $i$ at time $t$, given $\alpha_{i}$, can be written as:

$$
P\left[y_{i t}=1 \mid y_{i t-1}, x_{i t}, \bar{x}_{i}, \alpha_{i}\right]=\Phi\left[y_{i t-1}+x_{i t}^{\prime} \beta+\bar{x}_{i}^{\prime} a+\alpha_{i}\right]
$$

Estimation of equation (4), requires an assumption about the relationship between the initial values $y_{i 1}$ and individual-specific terms $\alpha_{i}$, because we should consider that households with adverse unobserved characteristics are more likely to be poor at the base year, inducing correlation between the error term and the lagged dependent variable $y_{i t-1}$, and thus leading to bias in parameter estimates (the initial conditions problem). More specifically treating the initial conditions as exogenous would result in an overestimation of state dependence measured by $\gamma$. Among the possible solutions to this problem, we follow two alternative specifications which are expected to produce similar results. ${ }^{8}$

Heckman (1981)'s approach allows initial conditions to be endogenous by specifying a linearised reduced form equation for the initial period of the latent variable:

$$
y_{i 1}^{*}=z_{i 1}^{\prime} \pi+\eta_{i}
$$

With $z_{i 1}$ being a vector that includes the explanatory variables at the base year jointly with a set of pre-sample instrumental variables, and where $\eta_{i}$ is correlated with $\alpha_{i}$, but uncorrelated with $u_{i t}$ for values of $t$ higher than one. Thus, using an orthogonal projection:

$$
\eta_{i}=\theta \alpha_{i}+u_{i 1}
$$

The parameter $\theta$ is always positive, unless initial conditions are exogenous, in which case equals zero, and $\alpha_{i}$ and $u_{i 1}$ would be independent from one another, while $u_{i 1}$ is assumed to

\footnotetext{
${ }^{8}$ See Arulampalam and Stewart (2009) and Akay (2009).
} 
satisfy the same distributional assumptions as $u_{i t}$ for the subsequent periods after the initial one.

Therefore, the reduced form of the latent variable in the initial period can be specified as:

$$
y_{i 1}^{*}=z_{i 1}^{\prime} \pi+\theta \alpha_{i}+u_{i 1}
$$

Therefore, the main equation (4) is estimated jointly with the initial period equation (8), allowing for cross-correlation of the error terms:

$$
P\left[y_{i 1}=1 \mid z_{i 1}, \alpha_{i}\right]=\Phi\left[z_{i 1}^{\prime} \pi+\theta \alpha_{i} \mid\right.
$$

Under the normalization used, $\sigma_{\alpha}=\sqrt{\lambda /(1-\lambda)}$ and since $\alpha$ is taken to be normally distributed, the maximum likelihood over $i$ can be evaluated using Gaussian-Hermite quadrature (Butler and Moffitt, 1982). This model has been used in a variety of areas such as unemployment and low pay dynamics but to the best of our knowledge it has never been estimated in the context of poverty dynamics.

Alternatively, a different solution to the initial conditions problem is the conditional maximum likelihood estimator proposed by Wooldridge (2005), which replaces the model for $y_{i 1}$ given $\alpha_{i}$ in Heckman approach by another one for $\alpha_{i}$ given $y_{i 1}$ :

$$
\alpha_{i}=b_{0}+b_{1} y_{i 1}+\xi_{i}
$$

where $\xi_{i} \sim$ iid $N\left(0, \sigma_{\xi}^{2}\right)$ is a new individual-specific term which is uncorrelated with the initial observation $y_{i 1}$ (and thus also uncorrelated with the lag of poverty status $y_{i t-1}$ ). The underlying model can be written as:

$$
y_{i t}^{*}=\mathcal{Y}_{i t-1}+x_{i t}^{\prime} \beta+\bar{x}_{i}^{\prime} a+b_{0}+b_{1} y_{i 1}+\xi_{i}+u_{i t}
$$

which can be easily estimated using a standard random-effects probit ${ }^{9}$ :

\footnotetext{
${ }^{9}$ Empirical exercises of this methodology in the analysis of poverty dynamics can be found in Devicienti and Poggi (2007), Andriopoulou and Tsakloglou (2008) and Ayllón (2009).
} 


$$
P\left[y_{i t}=1 \mid y_{i t-1}, x_{i t}, \bar{x}_{i}, y_{i 1}, \xi_{i}\right]=\Phi\left[\not y_{i t-1}+x_{i t}^{\prime} \beta+\bar{x}_{i}^{\prime} a+b_{0}+b_{1} y_{i 1}+\xi_{i}\right]
$$

Finally, in order to measure the importance of specifying individual-specific effects to measure poverty persistence, and even if a standard pooled probit model is no longer the specification to choose if the panel-level variance component is significant, we will also estimate this simple model that ignores individual-specific effects in order to provide a useful reference point. ${ }^{10}$

\section{Estimations and Results}

In order to estimate all previous equations we have selected an unbalanced panel sample of individuals living in households whose head is between 16 and 65 years of age. Then we furtherly separated our sample in two, depending on whether or not their households included children at least once during the interview period. Estimates for the three poverty regressions are presented in Table 2. The first group of results in this table is obtained from the pooled probit model with no individual-specific random effects which provides consistent but inefficient estimates of the coefficients (see Biewen, 2004). The other two groups provide estimates of the dynamic random effects probit models assuming that initial conditions are endogenous following, respectively, Wooldridge and Heckman approaches. Estimates for the initial conditions equation for the Heckman model appear in Table A.4 in the Appendix. As it could be expected, both random effects models provide roughly similar results.

Explanatory variables are defined so that the reference categories characterize the situation of people living in a household whose head is a married native Spanish male with primary education, who is employed with a permanent contract in a low-skilled occupation.

\subsection{Model specification: unobserved heterogeneity and initial conditions}

Regarding model specification, we should note that the likelihood test formally proves that the proportion of the total variance contributed by the panel-level variance component in dynamic random effects models, $\lambda$, is significantly different from zero, which makes the panel estimator significantly different from the pooled estimator. In fact, unobserved individual characteristics $\left(\alpha_{i}\right)$ account for about 30 percent of the individual propensity to be

${ }^{10}$ All three models were estimated using Stata 10: Wooldridge model using the official xtprobit do-file, Heckman and pooled probit with redprob ado-file written by Mark Stewart. See Stewart (2006) for details. 
poor in different years according to the Heckman model, a percentage that drops slightly to 25-28 percent with Wooldridge specification. Further, the Wald test of parameter's joint significance for all time-mean variables checks that without them, estimators would be inconsistent due to significant correlation between the individual-specific random effects and the explanatory variables. Similarly, the Wald test for the joint significance of the set of instruments used in the of initial conditions' equation in the Heckman model confirms that initial conditions are identified by the instruments, avoiding to rely on non-linearities in the functional form.

\subsection{Poverty persistence: true state dependence}

The first issue we wanted to explore was to what extent the different poverty profiles of individuals in households with and without children (with household heads in an equivalent age range) could be a result of a significant different degree of state dependence in poverty, after adequately controlling for observed and unobserved heterogeneity and treating the initial conditions problem. This effect is captured by the estimate of $\gamma$ in equation 4 , see second row of Table 2. 
Table 2. Dynamic effects probit models of the probability of being poor at year $t$

\begin{tabular}{|c|c|c|c|c|c|c|c|c|c|c|c|c|c|c|c|c|c|c|}
\hline \multirow{3}{*}{$\begin{array}{l}\text { Households } \\
\text { poor at year } t=1\end{array}$} & \multicolumn{6}{|c|}{ Pooled Probit } & \multicolumn{6}{|c|}{ Wooldridge } & \multicolumn{6}{|c|}{ Heckman } \\
\hline & \multicolumn{3}{|c|}{$\begin{array}{l}\text { with children } \\
\text { Coeff. St. error }\end{array}$} & \multicolumn{3}{|c|}{$\begin{array}{l}\text { without children } \\
\text { Coeff. St. error }\end{array}$} & \multicolumn{3}{|c|}{$\begin{array}{l}\text { with children } \\
\text { Coeff. St. error }\end{array}$} & \multicolumn{3}{|c|}{$\begin{array}{l}\text { without children } \\
\text { Coeff. St. error }\end{array}$} & \multicolumn{3}{|c|}{$\begin{array}{l}\text { with children } \\
\text { Coeff. St. error }\end{array}$} & \multicolumn{3}{|c|}{$\begin{array}{l}\text { without children } \\
\text { Coeff. St. error }\end{array}$} \\
\hline & & & & & & & 0.610 & 0.032 & $\star *$ & 0.658 & 0.058 & & & & & & & \\
\hline poor lag (at year t-1) & 0.919 & 0.019 & ** & 1.038 & 0.030 & $* *$ & 0.411 & 0.029 & ** & 0.452 & 0.051 & ** & 0.426 & 0.028 & ** & .475 & 0.050 & ** \\
\hline college & 0.208 & 0.068 & $* *$ & -0.212 & 0.079 & $* *$ & -0.236 & 0.076 & $* *$ & -0.347 & 0.092 & $* *$ & -0.223 & 0.076 & $* *$ & 0.343 & 0.092 & ** \\
\hline secondary & -0.139 & 0.043 & $* *$ & -0.095 & 0.065 & & -0.157 & 0.048 & ** & -0.179 & 0.079 & $* *$ & -0.153 & 0.048 & $* *$ & -0.176 & 0.079 & ** \\
\hline head's age & 0.016 & 0.007 & ** & -0.036 & 0.009 & $* *$ & 0.031 & 0.010 & $* *$ & -0.035 & 0.012 & $* *$ & 0.031 & 0.010 & $* *$ & -0.036 & 0.012 & ** \\
\hline head's age s & 0.000 & 0.000 & ${ }^{* *}$ & 0.000 & 0.000 & ** & 0.000 & 0.000 & ** & 0.000 & 0.000 & ** & 0.000 & 0.000 & $* *$ & 0.000 & 0.000 & ** \\
\hline female & 0.200 & 0.052 & $* *$ & -0.024 & 0.057 & & 0.268 & 0.059 & ** & -0.007 & 0.066 & & 0.266 & 0.059 & ** & -0.015 & 0.066 & \\
\hline one adult & & & & -0.288 & 0.209 & & & & & -0.272 & 0.249 & & & & & -0.281 & 0.248 & \\
\hline single parent & 0.018 & 0.095 & & -0.097 & 0.127 & & 0.179 & 0.104 & * & -0.236 & 0.161 & & 0.166 & 0.104 & & -0.229 & 0.161 & \\
\hline other & -0.100 & 0.067 & & 0.105 & 0.092 & & -0.070 & 0.073 & & 0.089 & 0.107 & & -0.135 & 0.073 & $*$ & 0.095 & 0.107 & \\
\hline fixed-t & 0.552 & 0.053 & ** & 0.219 & 0.084 & $* *$ & 0.637 & 0.058 & $* *$ & 0.250 & 0.096 & $* *$ & 0.632 & 0.058 & $* *$ & .247 & 0.096 & ** \\
\hline self-emplo & 0.152 & 0.051 & ** & 0.147 & 0.079 & * & 0.230 & 0.057 & $* *$ & 0.097 & 0.092 & & 0.228 & 0.057 & $* *$ & 0.102 & 0.092 & \\
\hline unemployed & 0.334 & 0.053 & $* *$ & 0.235 & 0.082 & $* *$ & 0.389 & 0.059 & ** & 0.245 & 0.095 & $* *$ & 0.385 & 0.059 & ** & 0.252 & 0.094 & ** \\
\hline retirec & 0.394 & 0.064 & ** & 0.456 & 0.077 & $* *$ & 0.494 & 0.073 & ** & 0.510 & 0.092 & $* *$ & 0.487 & 0.073 & $* *$ & 0.525 & 0.092 & ** \\
\hline$\%$ wage & -0.222 & 0.072 & ** & -0.092 & 0.075 & & -0.687 & 0.081 & $\star *$ & -0.391 & 0.088 & $* *$ & -0.628 & 0.081 & $* *$ & -0.336 & 0.088 & $* *$ \\
\hline$\%$ une & 0.101 & 0.104 & & 0.158 & 0.118 & & & 0.113 & & 2 & 0.136 & $* *$ & 0.100 & 0.113 & & 14 & 36 & $* *$ \\
\hline$\%$ pension & -0.847 & 0.200 & $* *$ & -0.345 & 0.115 & $* *$ & -1.230 & 0.224 & $* *$ & -0.294 & 0.135 & $* *$ & -1.153 & 0.224 & $* *$ & -0.258 & 0.135 & * \\
\hline n. of & 0.094 & 0.024 & $* *$ & 0.232 & 0.037 & $* *$ & 0.078 & 0.026 & $* *$ & 0.211 & 0.042 & $* *$ & 0.088 & 0.026 & $* *$ & 16 & 0.042 & ** \\
\hline high & 0.085 & 0. & * & 28 & & * & & 0.052 & & & & $* *$ & 0.068 & & & & 83 & $* *$ \\
\hline medium ski & -0.096 & 0.036 & $* *$ & -0.232 & 0.060 & $* *$ & -0.151 & 0.039 & $* *$ & -0.354 & 0.071 & $* *$ & -0.148 & 0.039 & ** & -0.344 & 0.071 & ** \\
\hline immic & 0.061 & 0.188 & & -4.109 & 1.566 & $* *$ & 0.157 & 0.204 & & -5.120 & 2.554 & $* *$ & 0.163 & 0.204 & & -5.254 & 2.582 & ** \\
\hline$\%$ fix & -1.072 & 0.087 & ** & -0.868 & 0.127 & $* *$ & -1.191 & 0.095 & $* *$ & -1.164 & 0.155 & $* *$ & -1.178 & 0.095 & $* *$ & -1.147 & 0.155 & $* *$ \\
\hline$\%$ uner & 0.130 & 0.065 & ** & 0.108 & 0.095 & & 0.078 & 0.072 & & 0.088 & 0.115 & & 0.055 & 0.072 & & 0.086 & 0.114 & \\
\hline $\mathrm{m}$ (coll & -0.515 & 0.079 & ** & -0.142 & 0.094 & & -0.612 & 0.094 & $\star *$ & 0.029 & 0.120 & & -0.745 & 0.095 & ** & -0.020 & 0.120 & \\
\hline $\mathrm{m}(\mathrm{se}$ & -0.225 & 0.052 & ** & -0.328 & 0.086 & $* *$ & -0.258 & 0.064 & ** & -0.331 & 0.115 & ** & -0.313 & 0.065 & $* *$ & -0.389 & 0.115 & ** \\
\hline$m(f e$ & 0.292 & 0.074 & ** & -0.187 & 0.072 & $* *$ & 0.369 & 0.098 & ** & -0.371 & 0.099 & ** & 0.336 & 0.098 & ** & -0.415 & 0.098 & ** \\
\hline $\mathrm{m}(\mathrm{o}$ & & & & 0.731 & 0.222 & $* *$ & & & & 0.782 & 0.272 & ** & & & & & & $* *$ \\
\hline m(s & 0.399 & 0.131 & ** & 0.394 & 0.136 & $* *$ & 0.388 & 0.143 & $* *$ & 0.436 & 0.181 & ** & 0.482 & 0.160 & ** & 0.442 & 0.181 & ** \\
\hline m(other) & -0.048 & 0.076 & & 0.022 & 0.106 & & -0.029 & 0.091 & & 0.052 & 0.133 & & -0.028 & 0.090 & & 0.021 & 0.133 & \\
\hline m(fixed-term head) & 0.273 & 0.081 & $* *$ & 0.639 & 0.127 & ** & & 0.104 & ** & 0.735 & 0.167 & ** & & 05 & ** & & 0.168 & ** \\
\hline m(self-employed he & 0.528 & 0.057 & $* *$ & 0.750 & 0.088 & ** & 0.634 & 0.069 & ** & 1.000 & 0.112 & ** & 0.763 & 0.070 & ** & 1.079 & 0.113 & ** \\
\hline m(un & 0.579 & 0.084 & ** & 0.520 & 0.125 & $* *$ & 0.690 & 0.111 & $* *$ & 0.622 & 0.170 & ** & 0.923 & 0.112 & $* *$ & 0.658 & 0.170 & $* *$ \\
\hline m(reti & 0.379 & 0.090 & ** & 0.253 & 0.103 & $* *$ & 0.427 & 0.119 & $* *$ & 0.253 & 0.142 & * & 0.618 & 0.120 & $* *$ & 0.268 & 0.142 & * \\
\hline$m(\% r e$ & -2.312 & 0.108 & ** & -1.175 & 0.111 & $* *$ & -2.336 & 0.140 & $* *$ & -1.286 & 0.153 & ** & -2.608 & 0.141 & $* *$ & & 0.152 & ** \\
\hline $\mathbf{m}(\%$ & -0.397 & 0.164 & ** & -0.315 & 0.177 & * & -0.381 & 0.215 & * & -0.593 & 0.244 & ** & -0.411 & 0.216 & * & 85 & 0.245 & ** \\
\hline m(\% pension) & -1.411 & 0.246 & ** & -1.318 & 0.146 & $* *$ & -1.183 & 0.312 & ** & -1.512 & 0.204 & ** & -1.646 & 0.311 & ** & -1.774 & 0.205 & ** \\
\hline m(n. of members) & -0.102 & 0.025 & $* *$ & -0.293 & 0.039 & ** & -0.084 & 0.028 & ** & -0.279 & 0.045 & ** & -0.068 & 0.028 & ** & 80 & 0.045 & ** \\
\hline m(highly skilled) & -0.679 & 0.062 & ** & -0.170 & 0.092 & * & -0.774 & 0.077 & ** & -0.205 & 0.121 & * & -0.843 & 0.078 & $* *$ & -0.325 & 0.122 & ** \\
\hline killed) & -0.106 & 0.045 & ** & 0.186 & 0.074 & $* *$ & -0.109 & 0.055 & $* *$ & 0.378 & 0.098 & ** & -0.124 & 0.056 & $\star *$ & 0.289 & 0.098 & ** \\
\hline m(immigrant) & 0.239 & 0.237 & & 4.040 & 1.551 & $* *$ & 0.284 & 0.283 & & 5.341 & 2.547 & ** & 0.204 & 0.289 & & .510 & 2.574 & ** \\
\hline $\mathbf{m}(\%$ & 0.636 & 0.143 & $* *$ & -0.072 & 0.195 & & 0.780 & 0.187 & $* *$ & 0.151 & 0.284 & & 0.649 & 0.188 & $* *$ & 0.053 & 0.284 & \\
\hline $\mathbf{m}(\%$ une & 0.834 & 0.116 & ** & 0.692 & 0.153 & ** & 0.997 & 0.156 & $\star *$ & 1.145 & 0.230 & ** & 1.149 & 0.157 & ** & 1.182 & 0.230 & ** \\
\hline Intercept & -0.953 & 0.196 & ** & -0.038 & 0.205 & & -1.417 & 0.241 & $* *$ & 0.025 & 0.296 & & -1.315 & 0.260 & $* *$ & 0.316 & 0.295 & \\
\hline$\sigma_{\alpha}$ & & & & & & & 0.57 & 0.02 & $* *$ & 0.62 & 0.04 & ** & 0.62 & & & 0.66 & & \\
\hline$\lambda$ & & & & & & & 0.25 & 0.01 & ** & 0.28 & 0.02 & - & 0.28 & 0.01 & $* *$ & 0.30 & 0.03 & ** \\
\hline LR test: $\lambda=0$ & & & & & & & 371.8 & & & 143.0 & & & 1,638 & & & 1,758 & & \\
\hline$p$-value & & & & & & & 0 & & & 0 & & & 0 & & & 0 & & \\
\hline$\theta$ & & & & & & & & & & & & & 1.22 & 0.09 & ** & 1.06 & 0.12 & ** \\
\hline Log-lik & -14.515 & & & $-6,402$ & & & $-13,709$ & & & $-5,519$ & & & $-17,032$ & & & & & \\
\hline N. of person-years & 41,593 & & & 24,168 & & & 40,277 & & & 20,144 & & & 50,259 & & & 30,912 & & \\
\hline N. of persons & 8,990 & & & 6,192 & & & 8,651 & & & 5,087 & & & 9,004 & & & 7,848 & & \\
\hline
\end{tabular}

Notes: Significance: $* p<0.10, * * p<0.05$. These results are obtained for those present at least two waves in the panel (unbalanced panel). The Pooled Probit and the Wooldridge Probit model are estimated using all observations for $t>1$ only. Initial conditions for Heckman estimates are shown in Table A.4 in the Appendix. Coefficients for yearly dummies and variables with a large number of missing values are not reported. 
Results underline that the lagged poverty status is determinant to explain current poverty; the magnitude of the $\gamma$ estimates according to the Heckman specification of the model is similar for households with and without children ( 0.426 and 0.475 respectively) and each of them is strongly statistically different from zero. An important result here is that it appears that our results point at a rejection of the hypotheses that higher permanent poverty among households with children in Spain is the result of a stronger state dependence for individuals in households with children compared to individuals in households without them. Similarly, the higher poverty recurrence observed for individuals in households with children does not appear to come about through the effect of a relatively lower state dependence for this demographic group.

Results in Table 2 show that the lagged poverty status coefficient is largely overestimated in the pooled probit compared with random effects models. Given that the former model uses a different normalization, each coefficient estimate needs to be multiplied by $\sqrt{(1-\lambda)}$ to make it comparable with random effects estimates, i.e. a factor of about 0.83-0.85 in the case of Heckman's. Thus the pooled probit $\gamma$ estimates of 0.919 and 1.038 correspond to rescaled estimates of about 0.781 and 0.866 , respectively.

Further, initial conditions are undoubtedly endogenous: the cross-period correlation estimated in the Heckman model for the composite error term $(\theta)$ is significantly different from zero in both samples. Additionally, Wooldridge's estimation strategy interestingly shows that being poor at the base period ( $t=1$, initial conditions) is more important than being poor in the previous interview ( $t-1$, true state dependence) in order to explain poverty at any year in both samples.

\subsection{The impact of observed household characteristics on the probability of being poor}

We obtain that lower poverty risk is found associated with individuals living in households with a native-male-head with a high education attainment, having a relatively high number of household members' in permanent employment and/or working in skilled occupations or 
receiving pension benefits. Also, single parenthood or being alone is related to a higher individual's probability of being poor. ${ }^{11}$

Note, however, that according to the particular specification of our model, we have two distinct effects for most explanatory variables. First, we have the coefficients of timeaveraged variables introduced in the model in order to control for potential correlation between the unobserved individual-specific error term and any observable characteristics. These characteristics play an important role given that most of their coefficients are statistically significant and their magnitude often differs significantly depending on the presence of children in the household. The interpretation of the coefficients is different depending on the particular variable we consider. In the case of "relatively fixed" factors, such as sex or education of the household head, that only vary in a yearly basis if there is a change in the head of the household, these variables resume the underlying differences between households affecting their probability of being poor. In the case of "time-varying" covariates, such as those related with household members' labour market performance, they indicate the part of the effect of these characteristics which is most structural, i.e. the household has a generally bad or good performance in the labour market during the seven years.

Note that, in order to interpret the total effect of time-varying covariates we need to consider the effects of the variables that enter the estimation with their particular value any given year. These effects play a crucial role in the interpretation of time-varying factors because they indicate the immediate effect of having a particular characteristic in any specific year. In general, the sign of the coefficient associated with each of the time-averaged variables is the same as the sign of the coefficient associated with the corresponding year-specific variable, implying that: what helps individuals avoid poverty does a similar job in a particular year. However, there are some important exceptions to this rule that imply, for example, that being a household with a large percentage of fixed-term contracts during a seven year period increases the probability of being poor but an increase in the percentage of fixed-term contracts in a given year, in contrast, helps the household avoid poverty.

\footnotetext{
${ }^{11}$ Table A.3 in the Appendix reports means and standard error of all variables included in the regression. Poverty rates are higher among households with children. Heads in this type of households are on average about five years younger and more likely to be male compared with households without children, as well as to have similar education. They are employed in a higher proportion with permanent contract, and less likely to be retired. There are much more married couples heading households with children, and the size of these households is larger. The share of household members receiving income from different sources is smaller.
} 


\subsubsection{Differential socio-demographic factors explaining poverty depending on the presence of children}

Focusing on the different effects of the time-averaged variables on the probability of being poor of individuals belonging to the two different demographic groups, we find that head's college education, as well as employment in skilled occupations seems to protect individuals in households with children from poverty more effectively than the rest. Female household heads are associated with lower probability of poverty in the absence of children, while a female head is related with a higher poverty among households with children, which may be a direct consequence of a variety of difficulties females face in order to enter the labour market when raising children. ${ }^{12}$ For the same reason, the effect of having a female head in any given year, compared with a situation in which the head is male or, in other words, a change in the household head from male to female (which could be a result of a separation of a couple or death of the male partner) appears to aggravate the risk of poverty only for individuals living in households with children.

Regarding the effect of the family type on the risk of poverty, married couples appear to have a significantly lower poverty risk than one adult or single parent households. The timeaveraged effect of the number of household members is much more strongly negative for households without children thus associating a large number of household members with a significantly lower poverty risk for individuals in these households, probably because for these household types that means more potential earners, while in the case of households with children, a larger number of household members might mean more adults but also more kids. However, any increase in the number of members at any year pushes the poverty risk upwards, especially in families without children, indicating that these newcomers are more likely to be non earners.

Moving into more essentially time-varying factors we find that the timing of poverty differs across households depending on the presence of children. The highest poverty risk of individuals in households without children appears when the household head is relatively young, given the convex relationship between the risk of poverty and household head's age (with its minimum at 48 years of age). In contrast, the highest poverty risk is faced by

\footnotetext{
${ }^{12}$ Note that female heads in Spain are often either unmarried or divorced women. In the case they are married they often live with an unemployed or retired male partner.
} 
individuals in households with children when the head is around her 40s, given that, in this case, the relationship is concave.

\subsubsection{Poverty and labour market performance}

Turning to the results on labour market variables we should focus on the specific characteristics that distinguish the Spanish labour market in an international context. First, the Spanish unemployment rate has traditionally been one of the highest in the OECD with a high elasticity to the downturns in the evolution of economic cycle: it has remained relatively high in periods of strong economic growth (the floor was a 8 percent rate after twelve years of economic growth that started in 1995) while increasing rapidly in economic recessions. On the other hand, the rate of employees working with fixed-term contracts has also been one of the highest among developed countries since the 1980s when various labour reforms widened the potential use of temporary contracts. These fixed-term contracts have been widely used ever since despite public subsidies to shift employees to permanent contracts, producing a largely segmented labour market with about a third of the labour force confined in highly unstable jobs. Both labour instability sources, unemployment and fixed-term contracts, are more likely to affect young and unskilled workers than any other group while unemployment was for a long time particularly high among females; thus contributing to the correlation of these characteristics with the probability of being poor.

Our results show that according to the effect of time-averaged variables in our model, the coefficients of unemployment of the head (compared with the head being employed with a permanent contract) and of the share of unemployed household members, are higher for all individuals. We do not find any significant difference in the effects of the household head having a fixed-term contract (compared with a permanent one) across groups. ${ }^{13}$ Nevertheless, the share of household members with fixed-term contracts seems to significantly increase the risk of poverty in households with children where, additionally, the share of members with earnings appears to be particularly relevant in reducing the poverty risk. Thus, we find no significant difference in the effect of the sources of labour instability when they refer to the

\footnotetext{
${ }^{13}$ The information of the type of contract the individual holds in the labour market is available for all ECHP interviews but the first one (1994). In order to use this interesting information for the complete panel we have decided to impute the contract type for this first interview using the information of the same individual at her second and third interviews. Imputations seem to slightly under-estimate the rate of fixed-term contracts at first interview.
} 
household head. In contrast, focusing on the labour market situation of all household members we can conclude that accumulating unemployed members produces a similar increase in the individual's poverty risk whatever her household type, while being in a household with a large number of members holding a fixed-term contract increases the probability of poverty more strongly in the presence of children in the household.

Regarding the effect of specific year labour-related covariates, unemployment of the head in any given year increases the risk of poverty in both groups in a similar magnitude. In contrast, the share of fixed-term contract household members in a given year reduces it. Note that this last effect contrasts with the positive effect of the time-averaged variable. The reasoning behind this apparent contradiction is simple: Having a high percentage of fixed-term employees in a household is positively associated with poverty risk because members are engaged in cycles of concatenated fixed-term contracts and unemployment spells. However, for these households, having one member employed, even if temporarily, in a particular year is better than having that same individual in unemployment. The fact that the household head has a fixed-term job at any given year, when compared with having a permanent job, increases the risk of poverty significantly more when individuals are in a household with children. Thus, households with children experience a more intense negative structural impact of being a household whose members are prone to work with fixed-term contracts, but benefit more than households without children of the positive effect of having this type of employment at any given year. Interestingly, unemployment seems to affect households' poverty risk more equally, regardless of the presence of children.

\subsubsection{Income sources and poverty}

Regarding households' income sources, we find that there is no significant difference in the negative effect on the probability of poverty associated with the share of household members receiving a either a pension or an unemployment benefit when the time-averaged effect is considered. However, the impact of changes in the share of people receiving these benefits (the effect at any given year) significantly reduces poverty among households with children in the case of pensions, and increases poverty among childless households in the case of unemployment. There is, however, a negative effect on poverty of the share of wage earners which is significantly higher in the case of households with children. This is true for both 
time-averaged and yearly values of the variable. That is, wage earners appear to protect households with children from poverty more effectively which may come about as a consequence of having more dependants and being, a priori, at a higher risk of poverty.

\section{Conclusions}

In this paper we have documented that households with children in Spain face a higher poverty risk than households without children, mainly driven by a higher recurrence in poverty, which is the largest among a selected groups of EU countries. A first aim of this paper was to try to discover the role played by true state dependence in this feature. Results have underlined that the lagged poverty status is determinant to explain current poverty even if our results point at a rejection of the hypotheses that higher poverty recurrence observed for individuals in households with children does not appear to come about through the effect of a relatively lower state dependence for this demographic group. Similarly, the higher permanent poverty among households with children in Spain is not the result of a stronger state dependence for individuals in households with children compared to individuals in households without them.

A second aim of the paper was to analyse if there are significant differences in the effect of explanatory variables on the probability of leaving poverty for households with and without children in order to try to understand what is effectively driving the observed differences in the poverty risk. In fact, we believe that instability factors that characterize the Spanish labour market, such as the high unemployment rate and the outstandingly high rate of temporary jobs, may be particularly determinant in promoting chronic child poverty as far as they can be structural factors for some household types. However they could also be increasing poverty recurrence if household members enter and exit employment often while engaged in repeated cycles of temporary employment and unemployment. Our results show that according to the effect of time-averaged variables in our model, the coefficients of unemployment of the head (compared with the head being employed with a permanent contract) and of the share of unemployed household members, are higher for all individuals. We do not find any significant difference in the effects of the household head having a fixed-term contract (compared with a permanent one) across groups. Nevertheless, the share of household members with fixed-term contracts seems to significantly increase the risk of poverty in households with children 
where, additionally, the share of members with earnings appears to be particularly relevant in reducing the poverty risk. Thus, we find no significant difference in the effect of the sources of labour instability when they refer to the household head. In contrast, focusing on the labour market situation of all household members we can conclude that accumulating unemployed members produces a similar increase in the individual's poverty risk whatever her household type, while being in a household with a large number of members holding a fixed-term contract increases the probability of poverty more strongly in the presence of children in the household. 


\section{References}

Adserá, A. (2004) Changing fertility rates in developed countries. The impact of labour market institutions, Journal of Population Economics, 17: 17-43.

Akay, A. (2009) The Wooldridge Method for the Initial Values Problem Is Simple: What About Performance?, Discussion Paper, No 3943, Institute for the Study of Labour (IZA), Bonn.

Ahn, N. and Mira, P. (2001) Job bust, Baby bust? Evidence from Spain, Journal of Population Economics, 14: 505-521.

Andriopoulou, E. and Tsakloglou, P. (2008) Once Poor, Always Poor? Do Initial Conditions Matter? Evidence from the ECHP. Paper presented at the XXII Annual Conference of the European Society for Population Economics, London.

Arranz, J.M. and Cantó, O (2009) Measuring the effect of spell recurrence on poverty dynamics. Paper presented at the Annual Meeting of The European Society for Population Economics, 2009, Seville.

Arulampalam, W. and Stewart, M.B. (2009) Simplified implementation of the Heckman estimator of the dynamic probit model and a comparison with alternative estimators, Oxford Bulletin of Economics and Statistics (forthcoming).

Ayala, L., Martínez, R. and Sastre, M. (2006) Familia, infancia y privación social, Fundación FOESSA, Madrid.

Ayala, L. and Cantó, O. (2009) Políticas Económicas y Pobreza Infantil en Análisis y Propuestas sobre Pobreza Infantil en España, UNICEF, Madrid.

Ayllón, S. (2009) Modelling state dependence and feedback effects between poverty, employment and parental home emancipation among European youth, unpublished document.

Biewen, M. (2004) Measuring state dependence in individual poverty status: are there feedback effects to employment decisions and household composition?, Discussion Paper, No 1138, Institute for the Study of Labour (IZA), Bonn.

Butler, J.S. and Moffit, R. (1982) A computationally efficient quadrature procedure for the one factor multinomial probit model, Econometrica 50: 761-764.

Cantó, O. and Mercader, M. (2002) Child Poverty in Spain from the 70's to the 90's: a Static and Dynamic Approach, Journal of Applied Social Sciences Studies (Schmollers Jahrbuch), 121 Jg., Vol 4/2002: 543-578.

Cantó, O., Gradín, C. and Del Río, C. (2008) La Dinámica de la pobreza en España: Cronicidad, Transitoriedad y Recurrencia, Documento de Trabajo de la Fundación FOESSA, Madrid.

Cappellari, L. and Jenkins, S.P. (2004) Modelling Low Income Transitions, Journal of Applied Econometrics 19(5): 593-610. 
Cappellari, L. and Jenkins, S.P. (2008) The Dynamics of Social Assistance Receipt: Measurement and Modelling issues, with an Application to Britain, Discussion Papers, DIW Berlin, number 828.

Chamberlain, G. (1984) Panel data, in Handbook of Econometrics, Griliches Z, Intrilligator M (eds). North-Holland: Amsterdam.

Devicienti, F. and Poggi, A. (2007) Poverty and Social Exclusion: Two sides of the Same Coin or Dynamically Interrelated Processes, Working Paper, No. 62, LABOR.

Duncan, G.J., Gustafsson, B., Hauser, R., Schmauss, G., Messinger, H., Muffels, R., Nolan, B. and Ray J.C. (1993) Poverty Dynamics in Eight Countries, Journal of Population Economics 6: 215-234

Emery, R.E., Hetherington, E.M. and DiLalla, L. (1984) Divorce, children, and public policy. In H. Stevenson \& A. Siegel (Eds.), Child Development Research and Social Policy: 189-266. Chicago: University of Chicago Press.

Eurostat (2007), Joint report on Social Protection and Social Inclusion, Eurostat.

Gardiner, K. and Hills, J. (1999) Policy implications of new data on income mobility, The Economic Journal, 109: F91-F111.

Heckman, J. (1981) The incidental parameters problem and the problem of initial conditions in estimating a discrete time-discrete data stochastic process, in Structural Analysis of Discrete Data with Econometric Applications, Manski C, Mc Fadden D (eds.). The MIT Press Cambridge: 179-195.

Huston, A. C. (1991) Children in Poverty: Child development and public policy, Cambridge University Press.

Jenkins, S. J. and Schluter, C. (2003) Why are child poverty rates higher in Britain than in Germany? A longitudinal Perspective, The Journal of Human Resources, Vol. 38, No. 2, Special Issue on Cross-National Comparative Research Using Panel Surveys: 441-465.

Machin, S. (1998) Childhood disadvantage and Intergenerational transmissions of economic status, Chapter 4, in Exclusion, Employment and Opportunity, A. Atkinson / M.Hill (eds). CASE paper, No. 4. London: Suntory and Toyota International Centers for Economics and Related Disciplines, London School of Economics.

McLoyd, V.C. (1998) Socioeconomic disadvantage and child development, The American Psychologist, 53 (2): 185-204.

McLoyd, V.C. and Wilson, L. (1991) The strain of living poor: Parenting, social support, and child mental health, in Children in poverty, chapter 5, Huston, A.C. (ed.): 105-135.

Mundlak, Y. (1978) On the pooling of time series and cross section data, Econometrica 46: 69-85.

OCDE (2001) Employment Outlook, June, Chapter 2: When money is tight: poverty dynamics in OECD countries, OECD, Paris. 
OECD (2008) Does income poverty last over time? Evidence from longitudinal data, Chapter 6 in Growing Unequal? Income distribution and poverty in OECD countries, OECD, Paris.

Stewart, M. (2006) Maximum Simulated Likelihood estimation of Random Effects Dynamic Probit Models with Autocorrelated Errors. Stata Journal 6: 256--272.

Stewart, M. (2007) The interrelated dynamics of unemployment and low-wage employment, Journal of Applied Econometrics, 22: 511-531.

UNICEF (2005) Child Poverty in Rich Countries. Innocenti Report Card No 6. Florence: UNICEF Innocenti Research Centre.

Wooldridge, J.M. (2005) Simple Solutions to the Initial Conditions Problem for Dynamic, Nonlinear Panel Data Models with Unobserved Heterogeneity, Journal of Applied Econometrics 20: 3954. 


\section{APPENDIX}

Table A1. Panel Sample for Spain, ECHP (1994-2001).

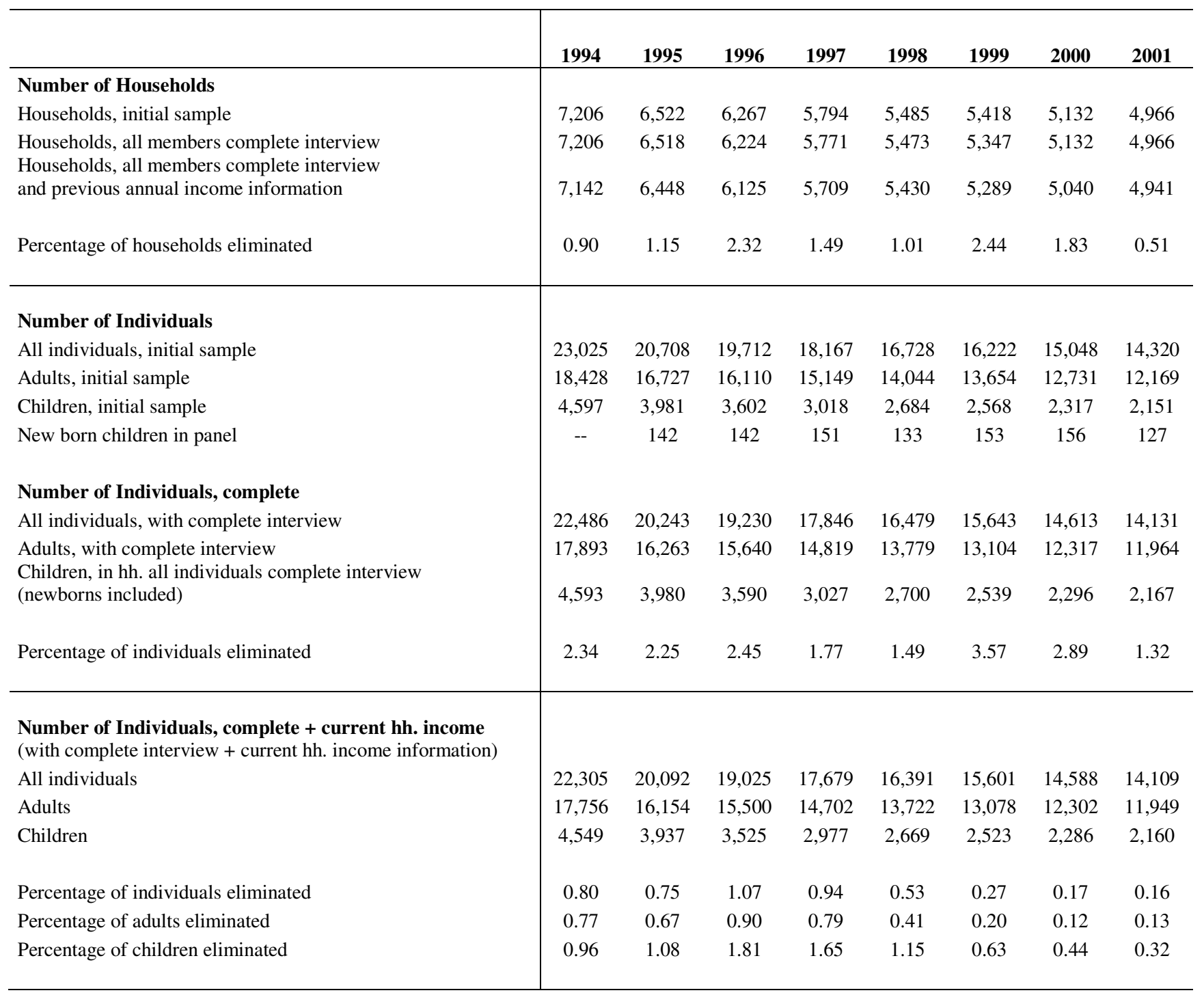

Source: Own construction using ECHP (1994-2001). 
Table A2. Final Panel Sample for Spain, ECHP (1994-2000), using contemporaneous information for household income and household characteristics

\begin{tabular}{|c|c|c|c|c|c|c|c|c|}
\hline & \multicolumn{8}{|c|}{ Different year of observation of household income $\&$ household characteristics } \\
\hline & 1993/1994 & $1994 / 1995$ & $1995 / 1996$ & $1996 / 1997$ & $1997 / 1998$ & 1998/1999 & $1999 / 2000$ & $2000 / 2001$ \\
\hline \multicolumn{9}{|c|}{$\begin{array}{l}\text { Number of Individuals, complete }+ \text { hh. income } \\
\text { (with complete interview }+ \text { hh. income information) }\end{array}$} \\
\hline All individuals & 22,305 & 20,092 & 19,025 & 17,679 & 16,391 & 15,601 & 14,588 & 14,109 \\
\hline Adults & 17,756 & 16,154 & 15,500 & 14,702 & 13,722 & 13,078 & 12,302 & 11,949 \\
\hline \multirow[t]{3}{*}{ Children } & 4,549 & 3,937 & 3,525 & 2,977 & 2,669 & 2,523 & 2,286 & 2,160 \\
\hline & \multicolumn{8}{|c|}{ Contemporary year of observation of household income $\boldsymbol{\&}$ household characteristics } \\
\hline & 1994 & 1995 & 1996 & 1997 & 1998 & 1999 & 2000 & \\
\hline \multicolumn{9}{|c|}{ FINAL SAMPLE (using contemporaneous income) } \\
\hline \multicolumn{9}{|c|}{$\begin{array}{l}\text { Number of Individuals, complete }+ \text { annual hh. income } \\
\text { (with complete interview }+ \text { annual hh. income information) }\end{array}$} \\
\hline All individuals & 19,044 & 17,754 & 16,496 & 15,402 & 14,519 & 13,740 & 13,251 & \\
\hline Adults & 15,042 & 14,216 & 13,374 & 12,800 & 12,088 & 11,489 & 11,147 & \\
\hline Children & 4,002 & 3,538 & 3,122 & 2,602 & 2,431 & 2,251 & 2,104 & \\
\hline Percentage of individuals eliminated & 14.62 & 11.64 & 13.29 & 12.88 & 11.42 & 11.93 & 9.17 & \\
\hline Percentage of adults eliminated & 15.28 & 12.00 & 13.72 & 12.94 & 11.91 & 12.15 & 9.39 & \\
\hline Percentage of children eliminated & 12.02 & 10.13 & 11.43 & 12.60 & 8.92 & 10.78 & 7.96 & \\
\hline
\end{tabular}

Source: Own construction using ECHP (1994-2001). 
Table A3. Means and standard errors of relevant variables, ECHP (1994-2001).

\begin{tabular}{|c|c|c|c|c|}
\hline \multirow[b]{2}{*}{ variable } & \multicolumn{2}{|c|}{ with children } & \multicolumn{2}{|c|}{ without children } \\
\hline & mean & St. Error & mean & St. Error \\
\hline poor & 0.23 & 0.002 & 0.14 & 0.002 \\
\hline poor lag & 0.23 & 0.002 & 0.13 & 0.002 \\
\hline college & 0.20 & 0.002 & 0.21 & 0.002 \\
\hline secondary & 0.16 & 0.002 & 0.14 & 0.002 \\
\hline primary & 0.64 & 0.002 & 0.65 & 0.003 \\
\hline head's age & 42.3 & 0.0 & 47.7 & 0.1 \\
\hline head's age squared & 1860.7 & 3.2 & 2427.8 & 6.2 \\
\hline female & 0.09 & 0.001 & 0.24 & 0.002 \\
\hline male & 0.91 & 0.001 & 0.76 & 0.002 \\
\hline one adult & & & 0.05 & 0.001 \\
\hline single parent & 0.04 & 0.001 & 0.13 & 0.002 \\
\hline married couple & 0.79 & 0.002 & 0.67 & 0.003 \\
\hline other household type & 0.16 & 0.002 & 0.14 & 0.002 \\
\hline missing & 0.00 & 0.000 & 0.01 & 0.001 \\
\hline employed head (permanent) & 0.47 & 0.002 & 0.38 & 0.003 \\
\hline employed head (fixed-term) & 0.13 & 0.002 & 0.12 & 0.002 \\
\hline self-employed (head) & 0.22 & 0.002 & 0.19 & 0.002 \\
\hline unemployed (head) & 0.10 & 0.001 & 0.12 & 0.002 \\
\hline retired (head) & 0.04 & 0.001 & 0.14 & 0.002 \\
\hline missing 1 & 0.01 & 0.000 & 0.03 & 0.001 \\
\hline missing 2 & 0.03 & 0.001 & 0.02 & 0.001 \\
\hline$\%$ receiving wage & 0.34 & 0.001 & 0.42 & 0.002 \\
\hline$\%$ receiving unemployment benefit & 0.05 & 0.001 & 0.06 & 0.001 \\
\hline$\%$ receiving pension & 0.03 & 0.000 & 0.15 & 0.001 \\
\hline N. of members & 4.52 & 0.006 & 3.51 & 0.008 \\
\hline highly skilled (head) & 0.25 & 0.002 & 0.23 & 0.002 \\
\hline medium skilled (head) & 0.40 & 0.002 & 0.31 & 0.003 \\
\hline Immigrant (head) & 0.01 & 0.000 & 0.00 & 0.000 \\
\hline$\%$ fixed term (members) & 0.10 & 0.001 & 0.10 & 0.001 \\
\hline$\%$ unemployed members & 0.10 & 0.001 & 0.12 & 0.001 \\
\hline 1994 & 0.17 & 0.002 & 0.22 & 0.002 \\
\hline 1995 & 0.17 & 0.002 & 0.19 & 0.002 \\
\hline 1996 & 0.16 & 0.002 & 0.15 & 0.002 \\
\hline 1997 & 0.14 & 0.002 & 0.13 & 0.002 \\
\hline 1998 & 0.13 & 0.001 & 0.12 & 0.002 \\
\hline 1999 & 0.12 & 0.001 & 0.10 & 0.002 \\
\hline 2000 & 0.11 & 0.001 & 0.09 & 0.002 \\
\hline no unemployment spell & 0.73 & 0.002 & 0.80 & 0.002 \\
\hline long unemployment spell & 0.13 & 0.002 & 0.12 & 0.002 \\
\hline 1 short unemployment spell & 0.06 & 0.001 & 0.03 & 0.001 \\
\hline $2+$ unemployment spells & 0.08 & 0.001 & 0.04 & 0.001 \\
\hline chronic health & 0.14 & 0.002 & 0.30 & 0.003 \\
\hline
\end{tabular}


Table A.4. Initial conditions regressions: the probability of being poor at the first year the household is observed in the panel $(t=1)$

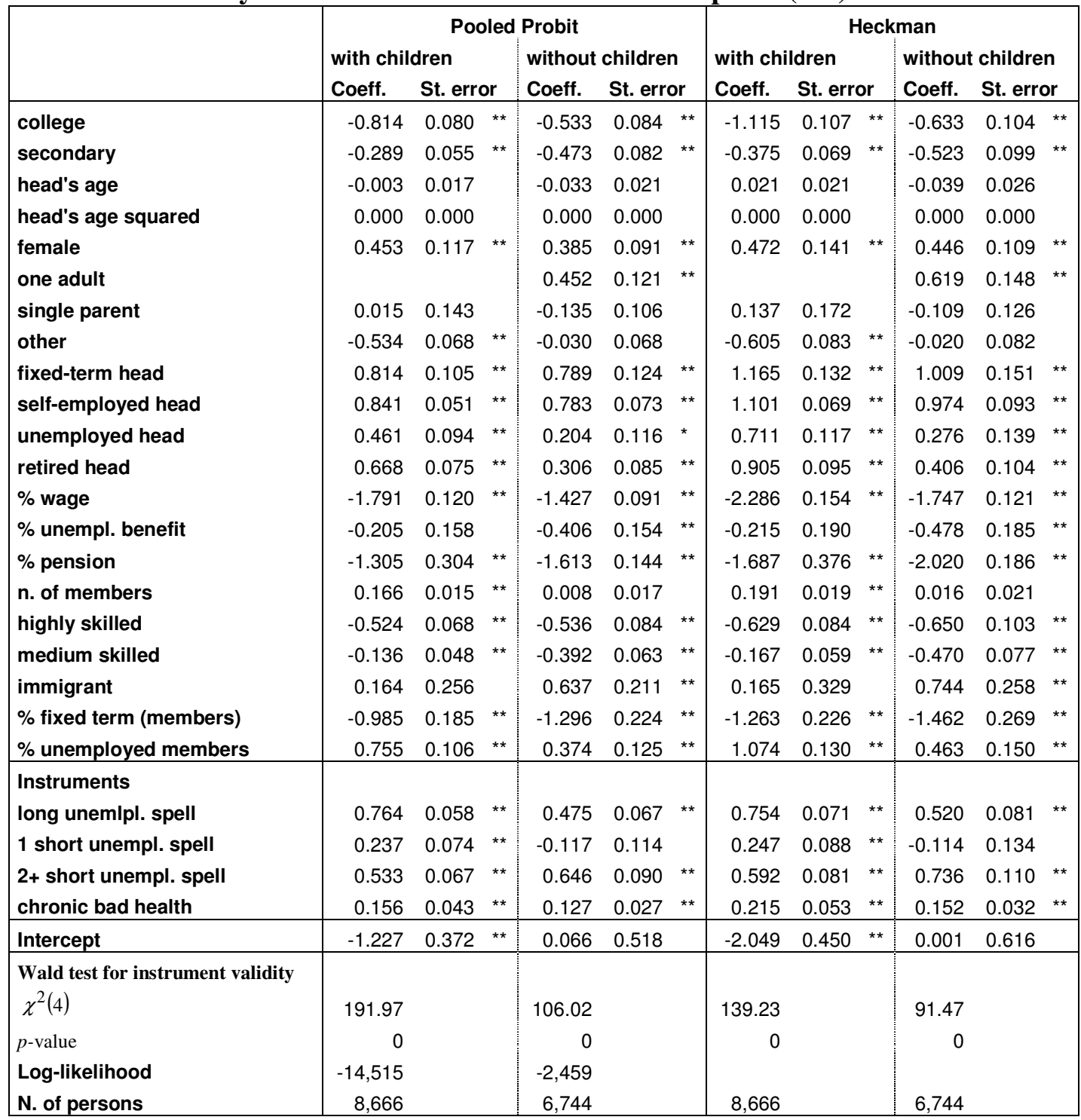

Notes: Significance: $* p<0.10$, ** $p<0.05$. Test for instruments validity is a Wald-type joint test for all instruments' coefficients being zero. Heckman's estimates are obtained jointly with the probability of being poor at $t>1$ reported in Table 5. Coefficients for yearly dummies and variables with a large number of missing values are not reported. 